\title{
Recovery, visoelastic and functional properties of Barbel skin gelatine: investigation of anti-DPP-IV and anti-prolyl endopeptidase activities of generated gelatine polypeptides
}

Assaâd Sila ${ }^{1}$, Oscar Martinez-Alvarez ${ }^{2}$, Anissa Haddar ${ }^{3}$, M. Carmen Gómez-Guillén ${ }^{2}$, Moncef Nasri ${ }^{4}$, M. Pilar Montero ${ }^{2}$ and Ali Bougatef

1 Unité Enzyme et Bioconversion, ENIS, University of Sfax, Tunisia.

2 Institute of Food Science, Technology and Nutrition (ICTAN-CSIC), Madrid, Spain.

3 Faculty of Sciences of Gabes, University of Gabes, Tunisia.

4 Laboratory of Microbiology and Enzyme Engineering, ENIS, University of Sfax, Tunisia.

5 Higher Institute of Biotechnology of Sfax PB 1175, 3038, Sfax Tunisia

*Corresponding author: Tel.: +216 74674 354; fax: 21674674 364;

E-mail addresses: ali.bougatef79@gmail.com 


\begin{abstract}
The characteristics and functional properties of gelatine from freshwater fish skin (Barbus callensis) were investigated. The gelatine extraction efficiency was improved by an acid-swelling process in the presence of barbel crude acid protease extract. Barbel skin gelatine (BSG) contained $92.15 \%$ protein, $0.31 \%$ lipid and $0.72 \%$ ash. The amino acid profile of BSG showed a high percentage of imino acids. The electrophoretic profile showed that BSG is mainly composed of $\alpha$ - and $\beta$-components. BSG showed an excellent solubility and possessed interfacial properties, which were governed by the protein concentration. Biological activities of the hydrolysates obtained after digestion of BSG with several commercial proteases were evaluated. The results suggested that these hydrolysates are a good source of natural inhibitors of dipeptidyl peptidase-IV and prolyl endopeptidase and could potentially be used as dietary ingredients in the management of type 2-diabetes and/or neuropathological disorders.
\end{abstract}

Keywords: Freshwater fish; gelatine; hydrolysates; dipeptidyl peptidase-IV; prolyl endopeptidase. 


\section{Introduction}

Gelatine is obtained by hydrolysis of collagen, the major constituent of connective tissue, skin and bones. Most commercial gelatines are derived from mammalian sources, mainly pigskin and cowhide; however, the interest in the use of fish gelatines is growing worldwide, mainly for sociocultural and safety considerations. The obtaining of fish gelatine is also of interest as it can be recovered from cost-effective sources, such as processing wastes or by-catches.

Different methods to extract gelatine have been described depending on the raw material used. Usually, acid/base solutions are used to extract gelatine of skins, bones or scales. Depending on the degree of collagen aggregation, the extraction process could also include the use of proteases (Bougatef, Balti, Sila, Nasri, Graiaa \& Nasri 2012) that together with a swelling step might lead to increments in the yield. However, at the same time, this step must be sufficiently soft to avoid an excessive fragmentation of the protein chains that could negatively affect the functional properties of the gelatine. That is why the gelatine extraction process must be adapted for each raw material used.

Gelatine quality for a particular application depends largely on its rheological properties (Stainsby 1987). Apart from basic physicochemical properties, such as composition parameters, solubility, transparency, colour, odour and taste, the main attributes that best define the overall commercial quality of gelatine are gel strength and thermal stability (gelling and melting temperatures). Both gel strength and thermostability are largely dependent on the molecular properties of gelatine, especially with respect to two main factors: the amino acid composition, which is species-specific, and the molecular weight distribution, which results mainly from processing conditions (Gómez-Guillén, Turnay, Fernández-Díaz, Ulmo Lizarbe \& Montero 2002). The proline and hydroxyproline content is particularly important for the gelling effect. Triple helical structure stability in renatured gelatines has been reported to be 
proportional to the total content in pyrrolidine imino acids, given that Pro + Hyp rich zones are involved in the formation of nucleation zones (Ledward 1986). Moreover, it has also been observed that the total Gly-Pro-Hyp sequence content is one of the main factors affecting collagen thermostability.

In the last decade, a large number of studies have been published reporting different biological activities of hydrolysates obtained from skin gelatine of aquatic species (Alemán, Giménez, Montero \& Gómez-Guillén 2011; Alemán \& Martínez-Alvarez 2013). However, the anti-diabetic, anti-depression and anti-Alzheimer effects of gelatine derived peptides or of gelatine hydrolysates have not been reported yet.

Dipeptidyl peptidase IV (DPP-IV) inhibitors represent a new class of antidiabetic agents that improve glycaemic control by blocking DPP-IV and thereby prolonging incretin effect in vivo (McIntosh, Demuth, Pospisilik \& Pederson 2005). Human and animal trials have demonstrated that DPP-IV inhibitors may increase the half-life of total circulating incretins and decrease plasma glucose, also improving glucose tolerance (Mitani, Takimoto, Hughes \& Kimura 2002). Treating diabetic animals with DPP-IV inhibitors also improves islet survival and maintains beta cell mass and islet function.

Prolyl endopeptidase (PEP), also known as prolyl oligopeptidase, is a highly conserved serine protease. Previous studies have suggested that abnormal PEP levels are related to neuropathological disorders, such as major depression, mania, schizophrenia and senile dementia of the Alzheimer's type. Inhibitors of PEP may improve memory by blocking the metabolism of endogenous neuropeptides (Tezuka, Fan, Kasimu \& Kadota 1999). These PEPinhibitors could be obtained by hydrolysis of different protein sources, including fish, as reported by Wilson, Hayes and Carney (2011).

The main objectives of this research were to extract BSG by using an endogenous barbel protease, to study its physicochemical characteristics as well as its functional 
properties, and also to explore the potential health benefits that could be derived from barbel gelatine. Within that context, both DPP-IV and PEP-inhibiting activities of different gelatine hydrolysates were investigated.

\section{Materials and methods}

\subsection{Chemicals}

Bovine haemoglobin, trichloroacetic acid, glycine, ammonium sulphate, bovine serum albumin, aprotinin, vitamin B12, hippuryl-L-histidyl-L-leucine, glycine, norleucine and DPPIV from porcine kidney were from Sigma Chemical Co. (St. Louis MO, USA). Sodium dodecyl sulphate (SDS), acrylamide, ammonium persulphate, N,N,N0,N0-tetramethyl ethylene diamine (TEMED), Coomassie Brilliant Blue R-250 were from Bio-Rad Laboratories (Hercules, CA, USA). Commercial proteases (esperase $0.8 \mathrm{~L}$, savinase $16 \mathrm{~L}$, alcalase $2.4 \mathrm{~L}$, trypsin, izyme $\mathrm{G}$, protamex and neutrase $0.8 \mathrm{~L}$ were kindly supplied by Novozymes (Bagsvaerd, Denmark). Peptidase was kindly supplied by Bio-Cat (Troy, VA, USA). Prolyl endopeptidase was from Seikagaku Corporation (Tokyo, Japan). The chromogenic substrates for DPP-IV and PEP (H-Gly-Pro-AMC $\bullet \mathrm{HBr}$ and Z-Gly-Pro-AMC respectively) were from Bachem (Bubendorf, Switzerland). Other chemicals and reagents used were of analytical grade.

\subsection{Preparation of barbel skin}

The barbel (Barbus callensis) used in this work were obtained from Barrage SIDI SAAD (Kairouan, Tunisia). They were packed in polyethylene bags, placed in ice and transported to the laboratory within $2 \mathrm{~h}$ after collection. Residual meat was removed manually from the skin, and the samples were washed with tap water. The skin was then cut into small pieces $(0.5 \times 0.5 \mathrm{~cm})$ and placed in polyethylene bags. Both the skin and stomach organs were stored at $20{ }^{\circ} \mathrm{C}$ until further use. 


\subsection{Preparation of barbel crude acid proteases}

Barbel crude acid protease was prepared as described by Bougatef, Balti, Ben Zaied, Souissi and Nasri (2008). The stomach of the barbel was rinsed with cold distilled water, cut into pieces with a thickness of $1-1.5 \mathrm{~cm}$ and then homogenized for $1 \mathrm{~min}$ with $10 \mathrm{mM}$ Tris$\mathrm{HCl}$ buffer $\mathrm{pH} 7.5(50 \%, \mathrm{w} / \mathrm{v})$. The homogenate was centrifuged at $10,000 \mathrm{xg}$ at $4{ }^{\circ} \mathrm{C}$ for 15 min (Rotina $380 \mathrm{R}$ centrifuge, Hettich, Germany). The pellet was discarded and the supernatant was collected and adjusted to $\mathrm{pH} 2.0$ with $1 \mathrm{M} \mathrm{HCl}$. The mixture was allowed to stand at $25{ }^{\circ} \mathrm{C}$ for $30 \mathrm{~min}$. The suspension was centrifuged at $5000 \mathrm{x} \mathrm{g}$ at $4{ }^{\circ} \mathrm{C}$ for $30 \mathrm{~min}$. The supernatant was then fractionated with ammonium sulphate (20-70\% saturation). The pellet was recovered by centrifuging at $10,000 \mathrm{x} \mathrm{g}$ for 10 min at $4{ }^{\circ} \mathrm{C}$. The precipitate was suspended in $50 \mathrm{mM}$ glycine $\mathrm{HCl}$ buffer $(\mathrm{pH} 2.0)$ and dialyzed for $24 \mathrm{~h}$ at $4{ }^{\circ} \mathrm{C}$ against repeated changes in the same buffer. The dialysate was used as crude acid protease extract. Proteolytic activity was assayed using haemoglobin as substrate by the method of Anson (1938) at $\mathrm{pH} 2.0$ and $40{ }^{\circ} \mathrm{C}$ for $15 \mathrm{~min}$. One unit of protease activity against haemoglobin was defined as the amount of enzyme that catalysed an increase in the absorbance at $280 \mathrm{~nm}$ of 1.0 unit per minute under the assay conditions.

\subsection{Extraction of BSG using the barbel proteases}

Gelatine was extracted according to the method of Nalinanon, Benjakul, Visesssanguan and Kishimura (2008) with a slight modification. Barbel skins were previously soaked in 0.05 $\mathrm{M} \mathrm{NaOH}(10 \% \mathrm{w} / \mathrm{v})$. The mixture was stirred for $2 \mathrm{~h}$ at room temperature, and the alkaline solution was changed every $30 \mathrm{~min}$. The alkaline-treated skins were then washed with distilled water until neutral $\mathrm{pH}$ was obtained. The alkaline-treated skins were soaked in $0.2 \mathrm{M}$ acetic acid with a ratio of 1:10 (w/v) and subjected to limited hydrolysis with barbel crude acid protease at levels of 20 units/g alkaline-treated skin. The mixtures were stirred for $48 \mathrm{~h}$ at $4{ }^{\circ} \mathrm{C}$. The $\mathrm{pH}$ of the mixtures was then raised to 7.5 using $10 \mathrm{M} \mathrm{NaOH}$. The mixtures were 
stirred at $4{ }^{\circ} \mathrm{C}$ for $1 \mathrm{~h}$ to terminate protease activity, and then incubated at $50{ }^{\circ} \mathrm{C}$ for $18 \mathrm{~h}$ with continuous stirring to extract the gelatine from the skin. The mixtures were centrifuged for 30 $\min$ at $10,000 \times \mathrm{g}$ using a refrigerated centrifuge to remove insoluble material. The supernatant was collected and lyophilized. The powder obtained was referred to as barbel skin gelatine (BSG).

\subsection{Characterization of barbel skin gelatine}

\subsubsection{Chemical composition}

The moisture and ash content were determined according to the AOAC standard methods 930.15 and 942.05, respectively (AOAC 2000). Total nitrogen content of BSG was determined according to the AOAC standard method 992.15 (Dumas method, AOAC 2000). Samples were heated to $1050{ }^{\circ} \mathrm{C}$ in a LECO model FP-2000 protein/nitrogen analyser calibrated with EDTA. Crude protein was estimated by multiplying total nitrogen content by a factor of 5.55. Crude fat was determined gravimetrically after Soxhlet extraction of dried samples with hexane. All measurements were performed in triplicate.

\subsubsection{Determination of colour}

The colour of films was determined with a tristimulus colorimeter (HunterLab D25 A-9, Hunter Associates Laboratory Inc., Reston, VA., USA) using the CIE Lab scale $\left(\mathrm{C} / 2^{\circ}\right)$ where $\mathrm{L}^{*}, \mathrm{a}^{*}$ and $\mathrm{b}^{*}$ are the parameters that measure lightness, redness and yellowness, respectively. A standard white plate with reflectance values of $L^{*}=93.68, a^{*}=-0.69, b^{*}=-0.88$, was used as reference. The results were the average of five measurements taken at ambient temperature at different points on the samples.

\subsubsection{Amino acid analysis}

BSG was dissolved $(1 \mathrm{mg} / \mathrm{ml})$ in ultrapure water and further hydrolysed in vacuumsealed glass at $110^{\circ} \mathrm{C}$ for $24 \mathrm{~h}$ in presence of continuously boiling $6 \mathrm{~N} \mathrm{HCl}$ containing $0.1 \%$ phenol and norleucine as internal standard. After hydrolysis, the sample was again vacuum- 
dried, dissolved in application buffer, and injected onto a Biochrom 20 amino acid analyser (Pharmacia, Barcelona, Spain). Results were expressed as number of residues per 1000 residues.

\subsubsection{Electrophoretic analysis}

SDS-polyacrylamide gel electrophoresis (SDS-PAGE) was performed as described by Laemmli (1970) using a 7\% (v/v) resolving gel and a 4\% (v/v) stacking gel. After electrophoresis, the gel was stained with $0.1 \%$ (w/v) Coomassie brilliant blue R-250, dissolved in distilled water, methanol and trichloroacetic acid $(5: 4: 1)$. The gel was destained using a solution containing methanol, distilled water, and acetic acid at a ratio of 5:4:1.

\subsection{Determination of functional properties}

\subsubsection{Viscoelastic properties}

Viscoelastic properties were performed on a Bohlin CRS-10 controlled stress rheometer rotary viscometer (Bohlin Instruments Ltd, Gloucestershire, UK) using a cone-plate geometry (cone angle $4^{\circ}$, gap $=0.15 \mathrm{~mm}$ ), according to Gómez-Guillén et al. (2002). A dynamic frequency sweep was done at $4^{\circ} \mathrm{C}$ by applying an oscillation amplitude within the linear region $(\gamma=0.005)$ over the frequency range $0.1-10 \mathrm{~Hz}$. The elastic modulus $\left(\mathrm{G}^{\prime} ; \mathrm{Pa}\right)$ and viscous modulus (G',; Pa) were determined as a function of angular frequency. To characterize the frequency dependence of $G^{\prime}$ and $G$ ', over the limited frequency range, the Power law model was used (Friedrich \& Heymann 1988):

$$
\mathrm{G}^{\prime}=\mathrm{G} 0 \text { ' } \omega \text {, }
$$

where G0' is the energy stored and recovered per cycle of sinusoidal shear deformation at an angular frequency of $1 \mathrm{~Hz}, \omega$ is the angular frequency and $\mathrm{n}$ is the power law exponent that should be near-zero for gels exhibiting an ideal elastic behaviour.

The dynamic temperature sweeps were done by cooling and heating from 40 to $5^{\circ} \mathrm{C}$ and back to $40{ }^{\circ} \mathrm{C}$, at a scan rate of $1{ }^{\circ} \mathrm{C} / \mathrm{min}$, frequency of $1 \mathrm{~Hz}$ and oscillating target strain 
$\gamma=0.005$. The elastic modulus $\left(\mathrm{G}^{\prime} ; \mathrm{Pa}\right)$, viscous modulus $\left(\mathrm{G}^{\prime}\right.$; $\left.\mathrm{Pa}\right)$ and phase angle $\left(\delta{ }^{\circ}{ }^{\circ}\right)$ were determined as a function of temperature. Gelling $(\mathrm{Tg})$ and melting $(\mathrm{Tm})$ temperatures were determined from the cross-point of $G^{\prime}$ and $G^{\prime}$ ' plots in the cooling and subsequent heating ramps, respectively.

\subsubsection{Gel strength}

Gel strength was determined according to Gómez-Guillén et al. (2002) using 6.67\% gels (w/v) formed by dissolving the dry gelatine in distilled water at $60{ }^{\circ} \mathrm{C}$ and cooling down the solution at $7{ }^{\circ} \mathrm{C}$ (maturation temperature) for $16-18 \mathrm{~h}$. The gel strength was determined at $7{ }^{\circ} \mathrm{C}$ using samples with $2.3 \mathrm{~cm}$ diameter and $3.6 \mathrm{~cm}$ height on an Instron model 4501 Universal Testing Machine (Instron Corp., Canton, MA, USA) with a load cell of $100 \mathrm{~N}$, cross-head speed $1 \mathrm{~mm} / \mathrm{s}$, and equipped with a $1.27-\mathrm{cm}$ diameter flat-faced cylindrical plunger. Gel strength was expressed as maximum force (in g) obtained when the plunger had penetrated $4 \mathrm{~mm}$ into the gelatine gels. Data represent the average $( \pm \mathrm{SD})$ of five determinations.

\subsubsection{Solubility}

Solubility of BSG was determined over a wide range of $\mathrm{pH}$ from 1 to 10 . Briefly, $200 \mathrm{mg}$ of BSG were suspended in $20 \mathrm{ml}$ of distilled water and the $\mathrm{pH}$ of the mixture was adjusted to the desired values with $6 \mathrm{~N} \mathrm{HCl}$ or $6 \mathrm{~N} \mathrm{NaOH}$. The mixtures were stirred at room temperature $\left(25 \pm 1^{\circ} \mathrm{C}\right)$ for $30 \mathrm{~min}$ and further centrifuged at $5000 \mathrm{x} \mathrm{g}$ for $15 \mathrm{~min}$. The nitrogen content in the supernatant was then determined by the Kjeldahl method (AOAC 2000). The solubility of BSG, defined as the amount of soluble nitrogen from the total nitrogen, was calculated as follows:

$$
\text { Nitrogen solubility }(\%)=\frac{\text { Supernatant nitrogen concentration }}{\text { Sample nitrogen concentration }} \times 100
$$




\subsubsection{Foaming properties}

The foam expansion (FE) and foam stability (FS) of BSG solutions (different concentrations from 0.5 to $4 \%$ ) were tested using a slightly modified version of the method described by Shahidi, Han \& Synowiecki (1995). Foam capacity was expressed as foam expansion at $0 \mathrm{~min}$, which was calculated according to the following equation:

$$
\mathrm{FE}(\%)=\frac{V_{T}-V_{0}}{V_{0}} \times 100
$$

Foam stability was calculated as the volume of foam remaining after 30 and $60 \mathrm{~min}$ using the following equation:

$$
\mathrm{FS}(\%)=\frac{V_{t}-V_{0}}{V_{0}} \times 100
$$

Where $\mathrm{V}_{\mathrm{T}}$ refers to the total volume after whipping $(\mathrm{ml}), \mathrm{V}_{0}$ to the volume before whipping, $\mathrm{V}_{\mathrm{t}}$ to the total volume after leaving at room temperature for different times (30 and $60 \mathrm{~min})$. The experiment was performed at least in duplicate.

\subsubsection{Emulsifying properties}

The emulsion activity index (EAI) and the emulsion stability index (ESI) of BSG were determined according to Pearce and Kinsella (1978). The gelatine solution was prepared by dissolving dry gelatine in distilled water at $60{ }^{\circ} \mathrm{C}$ for $30 \mathrm{~min}$. Thirty millilitres of the gelatine solution $1 \%(\mathrm{w} / \mathrm{v})$ were homogenised with $10 \mathrm{ml}$ of soybean oil at room temperature $\left(22^{\circ} \mathrm{C}\right)$ for 1 min using a Moulinex homogeniser. Aliquots of the emulsion were taken from the bottom container at 0 and $10 \mathrm{~min}$ after homogenization and diluted 100 -fold with $0.1 \%$ SDS solution. The mixtures were mixed thoroughly for 10 seconds and the absorbance of the diluted solutions was then measured at $500 \mathrm{~nm}$. The absorbance measured immediately $\left(\mathrm{A}_{0}\right)$ and 10 min $\left(\mathrm{A}_{10}\right)$ after emulsion formation was used to calculate the emulsifying activity index (EAI) and the emulsion stability index (ESI). All determinations are means of at least three measurements. 


\subsubsection{Water-holding and fat-binding capacities}

Water-holding capacity and fat-binding capacity were measured according to Lin, Humbert and Sosulki (1974) with slight modifications. BSG (0.5 g) was placed in a centrifuge tube and weighed (tube with gelatine). For measuring water-holding capacity and fat-binding capacity, $50 \mathrm{ml}$ of distilled water or $10 \mathrm{ml}$ of soybean oil were added, respectively, and held at room temperature for $1 \mathrm{~h}$. The gelatine solutions were mixed with a vortex mixer for 5 seconds every $15 \mathrm{~min}$. The gelatine solutions were then centrifuged at $4500 \mathrm{x} \mathrm{g}$ for $20 \mathrm{~min}$. The upper phases were removed and the centrifuge tubes were drained for $30 \mathrm{~min}$ on a filter paper after tilting to a $45^{\circ}$ angle. Water holding capacity and fat-binding capacity were expressed in $\mathrm{g}$ water/g sample and $\mathrm{g}$ oil/g sample, respectively.

\subsection{Barbel skin gelatine hydrolysates}

\subsubsection{Preparation of hydrolysates}

BSG $(2.5 \% \mathrm{w} / \mathrm{v})$ was dissolved in distilled water and subjected to enzymatic hydrolysis by using different commercial proteases. The reactions started by addition of the enzyme $(10 \%, w / w)$ under conditions outlined in Table 4 . The $\mathrm{pH}$ of the reaction was kept constant by using a pH-stat (TIM 856, Radiometer Analytical, Villeurbanne, France). After 90 min, hydrolyses were terminated by placing the samples in a water bath at $95{ }^{\circ} \mathrm{C}$ for $10 \mathrm{~min}$ with occasional agitation. The samples were then centrifuged at $3000 \mathrm{~g}$ for $15 \mathrm{~min}$. The supernatants were lyophilized and stored at $-80{ }^{\circ} \mathrm{C}$ for further assays.

\subsubsection{Determination of the degree of hydrolysis}

The degree of hydrolysis (DH), defined as the percent ratio of the number of peptide bonds cleaved $(h)$ to the total number of peptide bonds in the substrate studied $\left(h_{\text {tot }}\right)$, was calculated by the pH-stat method (Kristinsson \& Rasco 2000), according to the following equation:

$$
\mathrm{DH}(\%)=\frac{h}{h_{t o t}} \times 100=\frac{B \times N b}{M P} \times \frac{1}{\alpha} \times \frac{1}{h_{t o t}} \times 100
$$


Where $\mathrm{B}$ is the amount of $\mathrm{NaOH}$ consumed (ml) to keep the $\mathrm{pH}$ constant during the proteolysis of the substrate. $\mathrm{Nb}$ is the normality of the alkali, MP is the amount $(\mathrm{g})$ of protein (determined as $\mathrm{N} \times 5.55$ ), and $\alpha$ represents the average degree of dissociation of $\alpha-\mathrm{NH}_{2}$ groups. The total number of peptide bonds per unit weight $\left(\mathrm{h}_{\mathrm{tot}}\right)$ was calculated by determining the amino acid composition of the gelatine, and was found to be 11.12 meq $\mathrm{g}^{-1}$.

\subsubsection{Molecular weight distribution}

The molecular weight profile (MW) of each hydrolysate was obtained by size-exclusion HPLC (model SPE-MA10AVP, Shimadzu, Kyoto, Japan) on a Superdex peptide PC 3.2/30 column (GE Healthcare Bio- Sciences, Barcelona, Spain), with a fractionation range between 7000 and $100 \mathrm{Da}$. The mobile phase consisted of $30 \%(\mathrm{v} / \mathrm{v})$ acetonitrile with $0.01 \%(\mathrm{v} / \mathrm{v})$ TFA. The injection volume was $10 \mu \mathrm{l}$ and the flow rate was $25 \mu 1 / \mathrm{min}$. Optical density was measured at $214 \mathrm{~nm}$. Bovine serum albumin (BSA, $6700 \mathrm{Da}$ ), aprotinin (6512 Da), vitamin B12 (1340 Da), hippuryl-L-histidyl-L-leucine (429 Da) and Glycine (75 Da), were used as molecular weight standards.

\subsubsection{Assessment of the dipeptidyl peptidase-IV-inhibiting activity}

DPP-IV-inhibiting activity of the hydrolysates was measured according to Tulipano, Sibilia, Caroli and Cocchi (2011) with slight modifications. The assay was performed in a 96well plate. Briefly, $10 \mu \mathrm{l}$ of DPP-IV (previously diluted in $100 \mathrm{mM}$ tris $\mathrm{HCl}$ buffer, $\mathrm{pH} 8$ ) were incubated in the absence or in the presence of different concentrations of sample (final volume $300 \mu \mathrm{l}$ per well) at $37^{\circ} \mathrm{C}$ for $15 \mathrm{~min}$. The samples were previously diluted in $100 \mathrm{mM}$ Tris $\mathrm{HCl}$ buffer at $\mathrm{pH}$. The reaction started after addition of $100 \mu \mathrm{l}$ of assay buffer containing the chromogenic substrate $(\mathrm{H}-\mathrm{Gly}-\mathrm{Pro}-\mathrm{AMC} \cdot \mathrm{HBr})$ at a final concentration of 25 $\mu \mathrm{M}$. The change in fluorescence at $355 \mathrm{~nm} / 460 \mathrm{~nm}$ was monitored at 2-min intervals for 30 min in an Appliskan Multimode Microplate Reader (Thermo Fisher Scientific, MA, USA). Recorded data were plotted versus time. The inhibitory activity of the hydrolysates was 
calculated from the initial (maximal) slopes obtained in the absence or in the presence of test sample at different concentrations. Logarithmic regression was used to calculate the $\mathrm{IC}_{50}$ value, or concentration of samples needed to inhibit $50 \%$ of DPP-IV activity.

\subsubsection{Prolyl endopeptidas-inhibiting activity}

PEP-inhibiting activity of each hydrolysate was evaluated according to Yoshimoto, Walter and Tsuru (1980) with a slight modification. The assay was performed in a 96-well plate. Phosphate buffer $(0.1 \mathrm{M}, \mathrm{pH} 7.0$, EDTA $1 \mathrm{mM})$, PEP $(10 \mu$ ldiluted enzyme per test well) and phosphate buffer (control) or sample at different concentrations were mixed in a well and preincubated at $30^{\circ} \mathrm{C}$ for $15 \mathrm{~min}$. The reaction was started by adding $100 \mu \mathrm{l}$ of 0.01 $\mathrm{mM}$ of Z-Gly-Pro-AMC (chromogenic substrate). The change in fluorescence at $355 \mathrm{~nm} / 460$ $\mathrm{nm}$ was monitored at 2-min intervals for $30 \mathrm{~min}$ in an Appliskan Multimode Microplate Reader (Thermo Fisher Scientific, MA, USA). Recorded data were plotted versus time. The inhibitory activity of the hydrolysates was calculated from the initial (maximal) slopes obtained in the absence or in the presence of the test sample at different concentrations. Logarithmic regression was used to calculate the $\mathrm{IC}_{50}$ value, or concentration of hydrolysate needed to inhibit $50 \%$ of DPP-IV activity.

\subsection{Statistical Analysis}

Values are cited in the text as means $\pm \mathrm{SD}$. One-way ANOVA was performed to evaluate the statistical significance of the differences between mean $\mathrm{IC}_{50}$ value pairs using a significance level setting of $\mathrm{p} \leq 0.05$ (Statgraphics Centurion XV, Statpoint Technologies Inc., Virginia, USA). Correlation and regression analysis were carried out using EXCEL program. 


\section{Results and discussion}

\subsection{Gelatine extraction}

The gelatine extraction yield was $8.36 \%$ on the basis of wet weight. This yield was similar to those obtained for cuttlefish and smooth hound by Balti et al. (2011) and Bougatef et al. (2012), who also used endogenous proteases for gelatine extraction. An appropriate digestion of the raw collagen with proteases should improve the final gelatine yield of such a highly cross-linked collagen. Enzyme might solubilize the collagen in the skin matrix during the acid-swelling process, causing a looser structure that might ease the gelatine extraction, as described by Nalinanon et al. (2008). These authors also reported a marked increase in the yield of the gelatine extracted from Bigeye Snapper skin when pepsin was added during the swelling process with acetic acid compared to the yield of the gelatine extracted without enzyme.

\subsection{Proximate composition and colour of barbel skin gelatine}

The proximate composition of both fresh barbel skin and BSG are shown in Table 1 . Fresh barbel skin showed high protein content (25.24\%) and a moisture content of $66.31 \%$. The fat content of barbel skin was lower than $1 \%$. The protein content in BSG was very high $(92.15 \%)$. This content was higher than that reported for giant squid and cuttlefish skin gelatines (Gimenez et al. 2009; Balti et al. 2011). The moisture (5.63\%), fat (0.31\%) and ash $(0.72 \%)$ contents were low, suggesting efficient removal of fat and minerals from the skin material and good quality gelatine. The ash content of BSG was lower than the recommended maximum of $2.6 \%$ for gelatines.

The colour values of BSG are also shown in Table 1. In general, gelatine of interest to industry should have little colour. The $\mathrm{L}^{*}(74.67 \pm 0.16)$ and $\mathrm{b} *(10.02 \pm 0.09)$ values of BSG were significantly lower than those reported for bovine gelatine (Balti et al. 2011) but higher than those reported for gelatines from walking catfish and striped catfish skins (Jamilah et al. 
2011). This result suggests that pigments from barbel skin could be removed effectively during the pre-treatment performed before the gelatine extraction.

\subsection{Amino acid composition of gelatine}

The amino acid composition of BSG is shown in Table 2. BSG was rich in Pro, Gly and Hyp. Gly content represented approximately $33 \%$ of the total content of amino acids. The abundance of these amino acids in gelatines has been widely documented. As described by Asghar and Henrickson (1982), 50-60\% of $\alpha$-chains of collagen consist of tripeptides with the general formula Gly-X-Y, where $\mathrm{X}$ is generally Pro and $\mathrm{Y}$ is mainly Hyp. The imino acid content of BSG was higher than those reported in giant squid and Alaska Pollock gelatines (170 and 150 residues per 1000 residues, respectively) (Giménez, Gómez-Estaca, Aleman, Gòmez-Guillèn \& Montero 2009). However, this content was lower than those reported in Bigeye Snapper and giant catfish skin gelatines (195 and 211 residues per 1000 residues, respectively) (Jongjareonrak, Benjakul, Visessanguan \& Tanaka 2006; Jongjareonrak, Rawdkuen, Chaijan, Benjakul Osako \& Tanaka 2010). Further, the Hyp content in BSG (101 residues/1000) was higher than that reported in bovine gelatine (Bougatef et al. 2012) and also in grass carp fish scale gelatine (Zhang, Xu \& Wang 2011). The occurrence of a high proportion of imino acids in BSG is very important for the stability of the triple helical structure, as Pro + Hyp rich regions seem to be involved in the formation of nucleation zones (Ledward 1986). In particular, Hyp is believed to play a key role in the stabilization of the triple-stranded collagen helix due to its hydrogen bonding ability through its hydroxyl group. Pro and Ala were the most predominant hydrophobic amino acids, and similar values were found in gelatines from tuna skin and halibut, where the percentage of total hydrophobic amino acids were 64.7 and 63.7 respectively. Moreover, the content of essential amino acids in BSG was calculated, and it was found to be $12.5 \%$. 


\subsection{Electrophoretic profile of BSG}

The BSG was analysed by SDS-PAGE (Fig. 1). The electrophoretic profile mainly showed smear protein bands that could be products of hydrolysis of elementary chains of collagen. According to Gomez-Guillen et al. (2002), damage or partial loss of $\alpha 1$-chains can occur during the extraction procedure. BSG contained $\alpha_{1}$ and $\alpha_{2}$-chains as the major components. Moreover, $\beta$-chains were observed in BSG, while higher molecular weight polymers were almost absent. Additional smudged bands with molecular weight lower than $40 \mathrm{kDa}$ appeared below $\alpha$-chain, which could also be the result of hydrolysis of collagen.

\subsection{Functional properties of barbel skin gelatine}

\subsubsection{Viscoelastic properties and gel strength}

The gelling/melting behaviour of gelatine was assessed by dynamic oscillatory studies. Table 2 presents the main viscoelastic properties determined from both the angular frequency (measured at $5{ }^{\circ} \mathrm{C}$ ) and temperature (from 40 to $5{ }^{\circ} \mathrm{C}$ and back to $40{ }^{\circ} \mathrm{C}$ ) sweep tests. Gelatine showed a typical gel-like behaviour after a brief cold maturation period, since the elastic modulus $\left(G^{\prime}\right)$ prevailed over the viscous modulus $\left(G^{\prime \prime}\right)$ upon cooling, with phase angle $(\delta)$ at $5{ }^{\circ} \mathrm{C}$ of 0.851 . The mechanical spectra as a function of angular frequencies in the range of 0.1 to $10 \mathrm{~Hz}$ (data not shown) revealed that G' and G', values did successfully fit the Power law model ( $\mathrm{R} 2=0.95$ and 0.81 , respectively). G0' and G0', would indicate the resistance of the material to elastic and viscous deformation, respectively, at an angular frequency of $1 \mathrm{~Hz}$. The gelatine exhibited G0' and G0', values of $1021 \mathrm{~Pa}$ and $15.41 \mathrm{~Pa}$, respectively, which were intermediate between those registered in cod or hake (cold-water fish species) and sole or megrim (temperate-water fish species) (Gómez-Guillén et al. 2002) determined in similar experimental conditions. The frequency dependence of the cold matured gel was rather low, as denoted by the power law exponent n'=0.068, suggesting a well interconnected protein network conformation with suitable structural stability. For gels exhibiting an ideal elastic 
behaviour n' should be near-zero. An n' value of 0.064 has been reported previously for a commercial warm water skin gelatine at 4\% (w/v) concentration (Giménez et al. 2012).

From the cooling and subsequent heating ramps, the gelling ( $\mathrm{Tg}$ ) and melting ( $\mathrm{Tm})$ temperatures were found to be $10{ }^{\circ} \mathrm{C}$ and $22{ }^{\circ} \mathrm{C}$, respectively, which fall in the range corresponding to cold-water to temperate-water fish skin gelatines (Karim \& Bhat 2009). The complex viscosity $\left(\eta^{*}\right)$ of the newly dissolved gelatine at $40{ }^{\circ} \mathrm{C}$ was $0.017 \mathrm{~Pa}$, and turned to 0.031 after cold gelling and subsequent heating up to $40{ }^{\circ} \mathrm{C}$, indicating that although values were quite close, the gelling/melting behaviour was not fully reversible.

\subsubsection{Solubility}

Solubility is one of the most important functional properties of proteins and can also affect other functional properties, such as emulsification and foaming. The solubility profile exhibited a $U$ shaped curve in which high solubility values were obtained for a wide range of $\mathrm{pH}$ (data not shown). In acidic conditions ( $\mathrm{pH} 2-5)$, and at alkaline conditions ( $\mathrm{pH} 7-11)$ the solubility was around $80 \%$. Gelatine in solution may be covalently cross-linked to form matrices capable of swelling in the presence of aqueous solutions, forming what are commonly known as gelatine hydrogels (Gómez-Guillén et al., 2010). The lowest solubility was achieved at $\mathrm{pH} 6(67.36 \%)$, which probably corresponded to the isoelectric point of the BSG. This isoelectric point, very close to 7, confirmed that BSG was a type A gelatine. The $\mathrm{pH}$ affects the charge on the weakly acidic and basic side chain groups and proteins generally show low solubility at their isoelectric points. Solubility variations could be attributed to both net charge of proteins, which increase as $\mathrm{pH}$ moves away from the isoelectric point, and surface hydrophobicity, that promotes the aggregation via hydrophobic interaction.

\subsubsection{Foam capacity and foam stability}


Foam formation ability is another important property of gelatine of interest due to its potential application in foods. Foam expansion (FE) and foam stability (FS) of BSG are shown in Table 3. Foam expansion was determined at 0, 30, and $60 \mathrm{~min}$ after whipping to evaluate the foam capacity and stability of BSG. FE and FS of BSG increased with the increment of gelatine concentration. After 30 minutes of whipping, the amount of foam decreased in a range between 9 and 20\%, depending on the concentration used initially. After $60 \mathrm{~min}$, the loss was between 21 and $30 \%$. At the same concentrations, these values were lower than those of gelatine from cuttlefish skin (Balti et al. 2011) in spite of the similarity in percentage of hydrophobic amino acids (65.3). Foam expansion and foam stability of BSG were believed to be affected by the amount of hydrophobic amino acids (629 residues per 1000 residues, respectively). For adsorption at the air-water interface, molecules should contain hydrophobic regions which become more exposed upon protein unfolding, thus facilitating foam formation and stabilization (Townsend \& Nakai 1983). Foams with higher protein concentrations were denser and more stable, presumably because of an increase in the thickness of the interfacial films.

\subsubsection{Emulsifying properties}

The emulsifying activity index is a function of oil volume fraction and protein concentration. The emulsification process is the result of the absorption of proteins to the surface of freshly formed oil droplets during homogenization, forming a protective membrane that prevents droplets from coalescing. The emulsifying activity index (EAI) and emulsion stability index (ESI) of BSG at different concentrations $(0.5 \%, 1 \%, 2 \%, 3 \%$ and $4 \%$; w/v) are shown in Table 3. EAI of BSG increased with the increment of gelatine concentration. A high concentration of protein facilitated the protein adsorption at the interface. At similar concentrations, the EAI of BSG was lower than that reported for gelatine from smooth hound skin and bovine gelatine (Bougatef et al. 2012). Probably, this was the result of differences in 
the intrinsic properties, amino acid composition and conformation of the gelatines. High solubility of the protein in the dispersing phase increased the emulsifying efficiency, probably because the protein molecules were able to migrate to the surface of the fat droplets rapidly. As shown in Table 3, emulsions containing BSG were stable. However, the stability of these emulsions was lower than that of smooth hound skin gelatine (Bougatef et al. 2012). This fact was ascribed to differences in the intrinsic properties, amino acid composition (content of hydrophobic amino acids) and protein conformation among gelatines from different sources. Emulsion stability is related to the molecular weight of gelatine. Surh, Decker \& McClements (2006) reported that the oil-in-water emulsion prepared with high molecular weight fish gelatine $(\sim 120 \mathrm{kDa})$ was more stable than that prepared with low molecular weight fish gelatine $(\sim 50 \mathrm{kDa})$.

\subsubsection{Water-holding and fat-binding capacities}

Water-holding and fat-binding capacities are functional properties that are closely related to texture by the interaction between components such as water, oil and others. Waterholding and fat-binding capacities of BSG and commercial bovine gelatine were investigated. BSG showed a significantly higher fat-binding capacity $(3.42 \pm 0.09 \mathrm{~g}$ oil/g protein) but lower water-holding capacity $(2.98 \pm 0.33 \mathrm{~g}$ water/g protein) than that of commercial bovine gelatine $(2.76 \pm 0.17 \mathrm{~g}$ oil/g proteins and $3.21 \pm 0.46 \mathrm{~g}$ water/g protein, respectively). Similar results were reported by Balti et al. (2011) for gelatine from the skin of cuttlefish. The fatbinding capacity of BSG seemed to be dependent on the degree of exposure of the hydrophobic residues in BSG, which is close to $63 \%$. On the other hand, water-holding capacity seemed to be affected by smaller amounts of hydrophilic amino acids in the gelatine structure.

\subsection{Gelatine hydrolysates}




\subsubsection{Production of barbel skin gelatine hydrolysates}

Enzymatic proteolysis is a valuable bioprocess to enhance biological activities and functional properties of the original proteins, and some peptides generated from the hydrolysis possess stronger activity than others. Since proteases have specific cleavage positions on polypeptides chains, different enzymes were used (Table 4) to hydrolyze BSG and hence to produce peptides with different sequence and length. The enzymes were used at the same activity levels to compare hydrolytic efficiencies.

The hydrolysis of BSG was characterized by a high rate of hydrolysis during the initial $10 \mathrm{~min}$, slowing down thereafter until reaching a stationary phase when no apparent hydrolysis took place (data not shown). The high initial rate observed indicated that the maximum cleavage of peptides occurred within the first $10 \mathrm{~min}$ of hydrolysis. Similar hydrolysis patterns have been reported for enzymatic hydrolysis of different protein substrates (Sila et al., 2013). After 90 min of hydrolysis, the hydrolysis degree obtained was between 5.74 and $14.17 \%$. Alcalase was the most efficient enzyme to hydrolyze BSG, while izyme G was the lowest.

\subsubsection{Molecular weight distribution}

Analysis of the overall molecular weight distribution of the different hydrolysates is depicted in Fig. 2. The varying MW profiles revealed considerable differences in the degree of protein breakdown depending on the enzyme used. The izyme G, neutrase, trypsin and peptidase hydrolysates showed a higher content of peptides with MW above 3000 Da, whereas the hydrolysates obtained with esperase, savinase, protamex or alcalase mainly contained peptides with molecular weight below 3000 Da. The hydrolysate obtained with alcalase showed the lowest molecular weight components, which could be ascribed to the highest DH attained with this enzyme. It is worth noting that the hydrolysate obtained with izyme G did not contain the highest molecular weight components. 


\subsubsection{Assessment of DPP-IV and PEP-inhibiting activities}

The ability of the BSG hydrolysates to inhibit both DPP-IV and PEP activity was evaluated, and the results obtained are shown in Table 4.

All hydrolysates (excepting that obtained with Izyme G) exhibited similar $\mathrm{IC}_{50}$ levels $(\mathrm{P} \leq 0.05)$. That is, the DPP-IV inhibiting activity of the hydrolysates seemed not to be strongly influenced by the protease used. It is worth noting that the un-hydrolysed gelatine was unable to inhibit DPP-IV. The lowest $\mathrm{IC}_{50}$ value was obtained with Esperase $(2.21 \mathrm{mg}$ of dry weight $/ \mathrm{ml}$ ). Pieter (2006) has reported $\mathrm{IC}_{50}$ values that ranged from 0.4 to $5.0 \mathrm{mg} / \mathrm{ml}$ for different casein and lysozyme hydrolysates. Silveira, Martínez-Maqueda, Recio and Hernández-Ledesma (2013) have reported $\mathrm{IC}_{50}$ values of $1.51 \mathrm{mg} / \mathrm{ml}$ for a whey protein hydrolysate obtained with trypsin.

The gelatine hydrolysates also showed PEP-inhibiting activity (Table 4). Significant differences were found among samples $(\mathrm{p} \leq 0.05)$. The highest PEP-inhibiting activity $\left(\mathrm{IC}_{50}=0.91 \mathrm{mg} / \mathrm{ml}\right)$ was obtained with Trypsin, while the lowest was obtained with Peptidase $\left(\mathrm{IC}_{50}=3.79 \mathrm{mg} / \mathrm{ml}\right)$. The un-hydrolysed gelatine showed a negligible PEP-inhibiting activity $\left(\mathrm{IC}_{50}=73.97 \mathrm{mg} / \mathrm{ml}\right)$. The occurrence of PEP-inhibiting peptides in protein hydrolysates has been slightly documented; in fact, PEP-inhibiting peptides has been documented only in salmon, cod, trout and cheese hydrolysates (Sorensen et al., 2004).

The occurrence of Proline in the raw material seems to be important for producing DPP-IV and PEP-inhibitory peptides. In this sense, Proline is abundant in BSG and this fact could be important for producing DPP-IV and PEP-inhibitory peptides. It is worth noting that the enzymes used to hydrolyze BSG yielded peptides showing different inhibitory characteristics against both DPP-IV and PEP, even though both serine proteases belong to the prolyl oligopeptidase family. These differences in the inhibitory activity could be attributed to the impact of the enzyme's specificity, which is a key factor influencing both the 
characteristics of hydrolysates and the nature and composition of peptides produced. The use of esperase yielded a gelatine hydrolysate that showed low $\mathrm{IC}_{50}$ values for both PEP and DPPIV. This enzyme shows broad specificity and hydrolyses peptide bonds comprising the carboxylic groups of hydrophobic as well as hydrophilic residues (Georgieva, Stoeva, Voelter, Genov \& Betzel 2011). According to Wilson et al. (2011), it is possible that Esperase yields abundant peptides with Pro or Hyp at the P1 site that produces a higher inhibition of PEP and DPP-IV, when compared with the inhibitory effect of other hydrolysates.

The relationship between the hydrolysis degree and DPP-IV and PEP inhibitory activity of BSG hydrolysates was also studied. A relationship among the $\mathrm{DH}$ values and those of $\mathrm{IC}_{50}$ for either anti-PEP or anti-DPP-IV was not found, as depicted in Fig. 3. This means that the proximate molecular weight is not related to higher or lower inhibitory activity of the hydrolysates, independently of the enzyme used. Probably, it is the sequence (not the length) of determined peptides in the hydrolysates that is mainly responsible for their inhibitory activity.

\section{Conclusion}

In summary, it is possible to extract gelatine from barbel skin through a proteaseassisted process using a barbel acid-protease extract. This gelatine possesses interesting functional properties, including solubility, foam capacity, emulsion stability, fat-binding and water-holding capacity, which suggest that barbel skin gelatine could have interesting applications in food. Furthermore, barbel skin gelatine is a promising source of DPP-IV and PEP-inhibiting hydrolysates, with potential anti-diabetic and anti-Alzheimer applications in functional foods.

\section{Acknowledgments}


This work was funded by Ministry of Higher Education and Scientific Research, Tunisia, and also by the Spanish Ministry of Foreign Affairs (MAEC-AECID).

\section{References}

Alemán, A., \& Martínez-Alvarez, O. (2013). Marine collagen as a source of bioactive molecules. A review. The Natural Products Journal, 3, 105-114.

Alemán, A., Giménez, B., Montero, P., \& Gómez-Guillén, M. C. (2011). Antioxidant activity of several marine skin gelatines. LWT Food Science and Technology, 44, 407-413.

Anson, M. L. (1938). The estimation of pepsin, trypsin, papain, and the cathepsin with hemoglobin. Journal of General Physiology, 22, 79-89.

AOAC. (2000). Official methods of analysis, 17th edn. Association of Official Analytical.

Asghar, A., \& Henrickson, R. L. (1982). Chemical, biochemical, functional, and nutritional characteristics of collagen in food systems. In C. O. Chichester, E. M. Mrata, \& B. S. Schweigert (Eds.), Advances in food research (pp. 232-372). London: Academic Press.

Balti, R., Jridi, M., Sila, A., Souissi, N., Nedjar-Arroume, N., Guillochon, D., \& Nasri, M. (2011). Extraction and functional properties of gelatine from the skin of cuttlefish (Sepia officinalis) using smooth hound crude acid protease-aided process. Food Hydrocolloids, 25, 943-950.

Bougatef, A., Balti, R., Ben Zaied, S., Souissi, N., \& Nasri, M. (2008). Pepsinogen and pepsin from the stomach of smooth hound (Mustelus mustelus): purification, characterization and amino acid terminal sequences. Food Chemistry, 107, 774-784.

Bougatef, A., Balti, R., Sila, A., Nasri, R., Graiaa, G., \& Nasri, M. (2012). Recovery and physicochemical properties of smooth hound (Mustelus mustelus) skin gelatine. LWT Food Science and Technology, 48, 248-254.

Friedrich, C., \& Heymann, L. (1988). Extension of a model for crosslinking polymer at the gel point. Journal of Rheology, 32, 235-241. 
Georgieva, D. N., Stoeva, S., Voelter, W., Genov, N., \& Betzel, C. (2001). Substrate specificity of the highly alkalophilic bacterial proteinase esperase: relation to the x-ray structure. Current Microbiology, 42, 368-371.

Giménez, B., Gómez-Estaca, J., Aleman, A., Gòmez-Guillèn, M. C., \& Montero, M. P. (2009). Physico-chemical and film forming properties of giant squid (Dosidicus gigas) gelatinee. Food Hydrocolloids, 23, 585-592.

Giménez, B., Gómez-Guillén, M. C., López-Caballero, M. E., Gómez-Estaca, J. \& Montero, P. (2012). Role of sepiolite in the release of active compounds from gelatine-egg white films. Food Hydrocolloids, 27, 475-486.

Gómez-Guillén, M. C., Giménez, B., López-Caballero M. E., \& Montero, M. P. (2011). Functional and bioactive properties of collagen and gelatine from alternative sources: A review. Food Hydrocolloids, 25, 1813-1827.

Gómez-Guillén, M. C., López-Caballero, M. E., Alemán, A., López de Lacey, A., Giménez, B., \& Montero, P. (2010). Antioxidant and antimicrobial peptide fractions from squid and tuna skin gelatine. In E. Le Bihan (Ed.), Sea by-products as real material: New ways of application (pp. 89-115). Kerala, India: Transworld Research Network.

Gómez-Guillén, M. C., Turnay, J., Fernández-Díaz, M. D., Ulmo, N., Lizarbe, M. A., \& Montero, P. (2002). Structural and physical properties of gelatine extracted from different marine species: a comparative study. Food Hydrocolloids, 16, 25-34.

Jamilah, B., Tana, K. W., Umi Hartina , M. R., a Azizah, A. (2011). Gelatines from three cultured freshwater fish skins obtained by liming process. Food Hydrocolloids, 25, 1256-1260.

Jongjareonrak, A., Benjakul, S., Visessanguan, W., \& Tanaka, M. (2006). Skin gelatine from bigeye snapper and brownstripe red snapper: chemical compositions and effect of microbial transglutaminase on gel properties. Food Hydrocolloids, 20, 1216-1222. 
Jongjareonrak, A., Rawdkuen, S., Chaijan, M., Benjakul, S., Osako, K., \& Tanaka, M. (2010). Chemical compositions and characterisation of skin gelatine from farmed giant catfish (Pangasianodon gigas). LWT - Food Science and Technology, 43, 161-165.

Karim, A.A., \& Bhat, R. (2009). Fish gelatine: properties, challenges, and prospects as an alternative to mammalian gelatines. Food Hydrocolloids, 23, 563-576.

Kristinsson, H. G., \& Rasco B. A. (2000). Fish Protein Hydrolysates: Production, Biochemical, and Functional Properties. Critical Reviews in Food Science and Nutrition, 40, 43-81.

Laemmli, U. K. (1970). Cleavage of structural proteins during the assembly of head of bacteriophage T4. Nature, 227, 680-685.

Ledward, D. A. (1986). Gelation of gelatine. In J. R. Mitchell, \& D. A. Ledward (Eds.). Functional properties of food macromolecules (pp. 171-201). London: Elsevier Applied Science Publishers.

Lin, M. H. Y., Humbert, E. S., \& Sosulki, F. W. (1974). Certain functional properties of sunflower meal products. Journal of Food Science, 39, 368-370.

McIntosh, C., Demuth, H. U., Pospisilik, A. J., \& Pederson, R., (2005). Dipeptidyl peptidase IV inhibitors: How do they work as new antidiabetic agents. Regulatory Peptides, 128, $159-165$.

Mitani, H., Takimoto, M., Hughes, T. E., \& Kimura, M. (2002). Dipeptidyl peptidase IV inhibition improves impaired glucose tolerance in high-fat diet-fed rats: study using a Fischer 344 rat substrain deficient in its enzyme activity. Japanese Journal of Pharmacology, 88, 442-450.

Nalinanon, S., Benjakul, S., Visesssanguan,W., \& Kishimura, H. (2008). Improvement of gelatine extraction from bigeye snapper skin using pepsin-aided process in combination with protease inhibitor. Food Hydrocolloids, 22, 615-622. 
Pearce, K. N., \& Kinsella, J. E. (1978). Emulsifying properties of proteins: Evaluation of a turbidimetric technique. Journal of Agricultural and Food Chemistry, 26, 716-723.

Pieter, B. J. W. (2006). Protein hydrolysate enriched in peptides inhibiting DPP-IV and their use. WO 2006/068480 200.

Shahidi, F., Han, X. Q., \& Synowiecki, J. (1995). Production and characteristics of protein hydrolysates from capelin (Mallotus villosus). Food Chemistry, 53, 285-293.

Sila, A., Haddar, A., Martinez-Alvarez, O., \& Bougatef, A. (2013). Angiotensin-I-Converting Enzyme Inhibitory and Antioxidant Activities of Protein Hydrolysate from Muscle of Barbel (Barbus callensis). Journal of Chemistry, (Article ID 545303).

Silveira, S, T., Martínez-Maqueda, D., Recio, I., \& Hernández-Ledesma, B. (2013). Dipeptidyl peptidase-IV inhibitory peptides generated by tryptic hydrolysis of a whey protein concentrate rich in $\beta$-lactoglobulin. Food Chemistry, 141, 1072-1077.

Sorensen, R., Kildal, E., Stepaniak, L., Pripp, A. H., \& Sorhaug, T. (2004). Screening for peptides from fish and cheese inhibitory to prolyl endopeptidase. Nahrung/Food, 48, 53-56.

Stainsby, G. (1987). Gelatine gels. In A. M. Pearson, T. R. Dutson, \& A. J. Bailey (Eds.), Advances in meat research, collagen as a food, (pp. 209-222). New York: Van Nostrand Reinhold Company Inc.

Surh, J., Decker, E. A., \& McClements, D. J. (2006). Properties and stability of oilinwater emulsions stabilized by fish gelatine. Food Hydrocolloids, 20, 596-606.

Tezuka, Y., Fan, W., Kasimu, R., \& Kadota, S. H. (1999). Screening of crude drug extracts for prolyl endopeptidase inhibitory activity. Phytomedicine, 6, 197-203.

Townsend, A. A., \& Nakai, S. (1983). Relationships between hydrophobicity and foaming characteristics of food proteins. Journal of Food Science, 48, 588-594. 
Tulipano, G., Sibilia, V., Caroli, A. M., \& Cocchi, D. (2011). Whey proteins as source of dipeptidyl dipeptidase IV (dipeptidyl peptidase-4) inhibitors. Peptides, 32, 835-838.

Wilson, J., Hayes, M., \& Carney, B. (2011). Angiotensin-I-converting enzyme and prolyl endopeptidase inhibitory peptides from natural sources with a focus on marine processing by-products. Food Chemistry, 129, 235-244.

Yoshimoto, T., Walter, R., \& Tsuru, D. (1980). Proline-specific endopeptidase from Flavobacterium. Purification and properties. Journal of Biological Chemistry, 255, 4786-4792.

Zhang, F., Xu, S., \& Wang, Z. (2011). Pre-treatment optimization and properties of gelatine from freshwater fish scales. Food and bioproducts processing, 89, 185-193. 
Fig. 1. Electrophoretic profile of the barbel skin gelatin at $2 \mathrm{mg}$ protein $/ \mathrm{mL} . \beta=\beta$-chain; $\alpha_{1}=\alpha_{1}$-chain; $\alpha_{2}=\alpha_{2}$-chain.

Fig. 2. Molecular weight profile of the barbel skin gelatin hydrolysates, treated with various commercial proteases. Optical density was measured at $214 \mathrm{~nm}$.

Fig. 3. Relationship between the estimated main molecular weight of the hydrolysates and the DH values (A), DPP-IV-inhibiting activity (B) and PEP-inhibiting activity (C). 
Fig. 1.

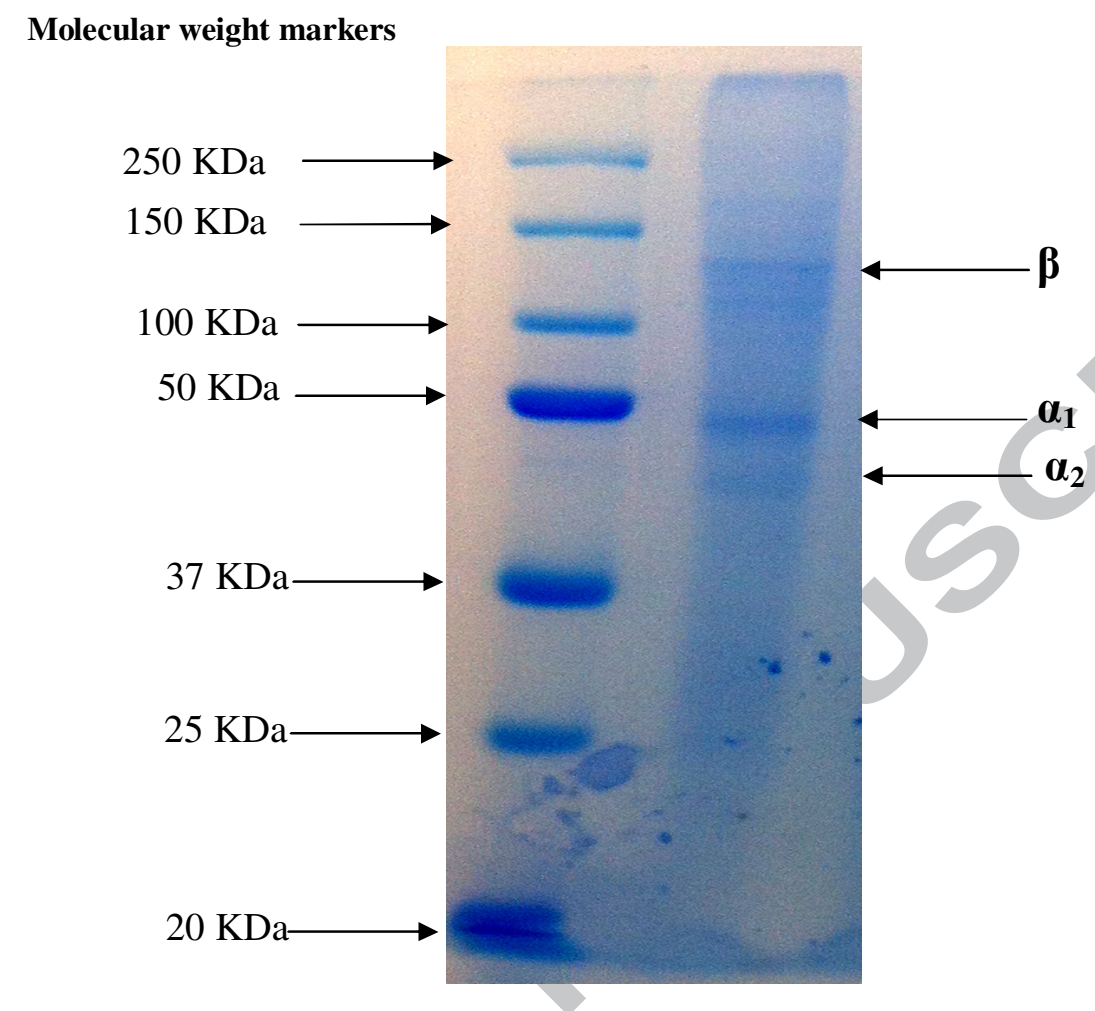


Fig. 2.
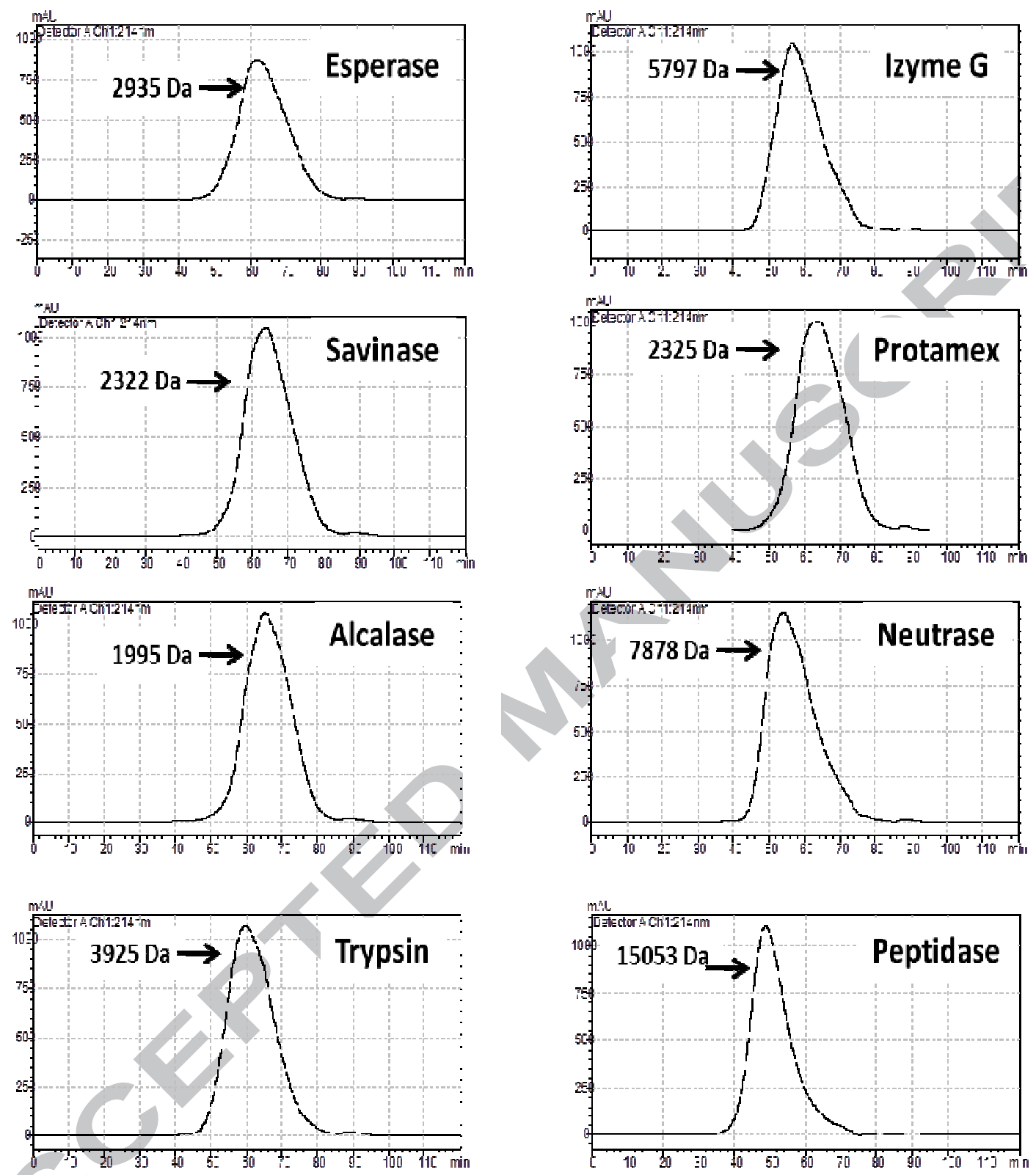
Fig. 3.

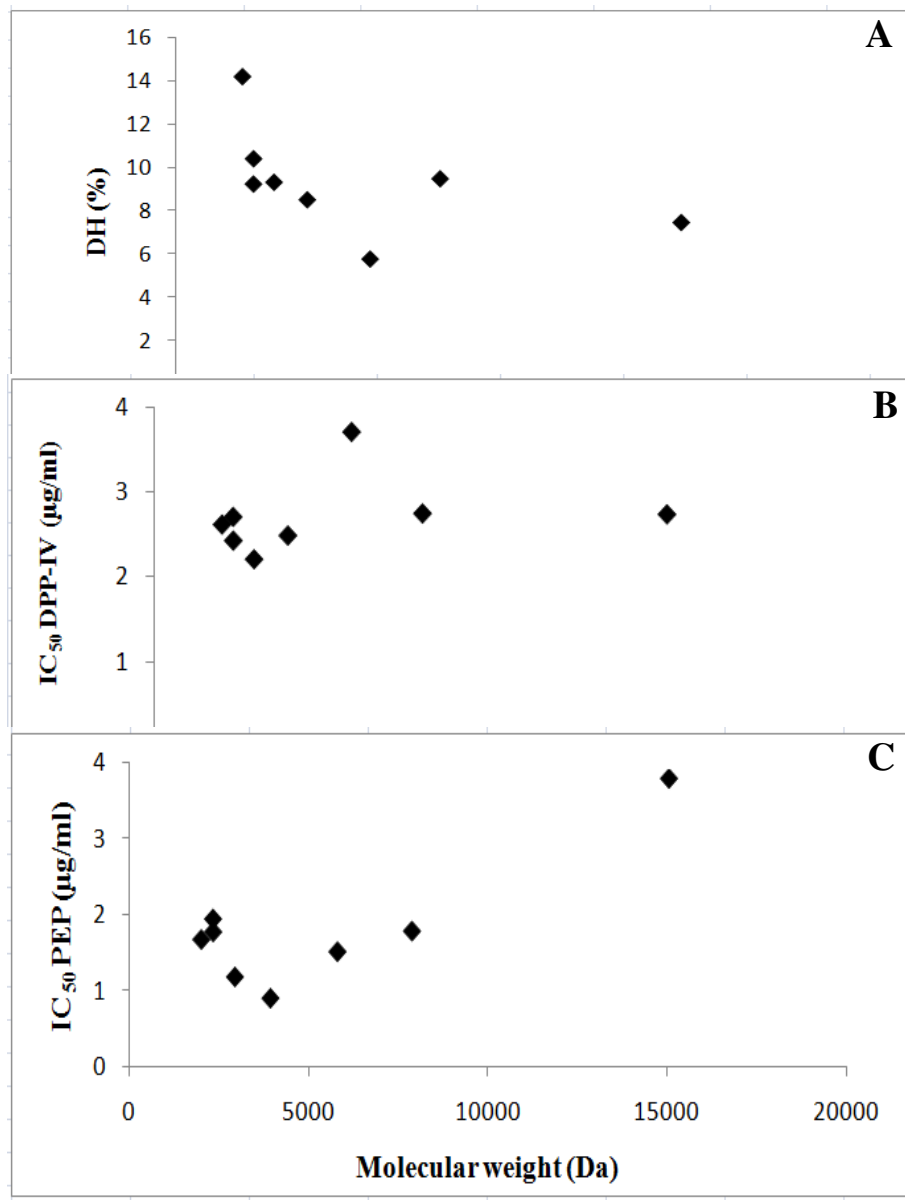


Table 1. Proximate composition, colour and amino acid composition of barbel skin gelatine (BSG).

\begin{tabular}{ccc}
\hline Composition & Barbell skin & BSG \\
\hline Moisture (\%) & $66.31 \pm 1.8$ & $5.63 \pm 0.5$ \\
Protein (\%) & $25.24 \pm 2.2$ & $92.15 \pm 0.61$ \\
Fat (\%) & $0.45 \pm 0.02$ & $0.31 \pm 0.01$ \\
Ash (\%) & $2.76 \pm 0.3$ & $0.72 \pm 0.03$ \\
& & \\
Colour & & \\
L* & - & $-1.01 \pm 0.01$ \\
$\mathrm{a}^{*}$ & - & $10.02 \pm 0.09$ \\
$\mathrm{~b}^{*}$ & - &
\end{tabular}

Amino acids

Number of residues/1000

$\operatorname{Asx}(\mathrm{D}+\mathrm{N})$

45

Thr (T)

24

Ser (S)

46

Glx $(E+Q)$

68

Gly $(\mathrm{G})$

354

Ala (A)

Cys (C)

Val (V)

119

Met (M)

1

Ile (I)

Leu (L)

Tyr (Y)

15

9

20

Phe (F)

3

OHLys

13

His (H)

7

Lys (K)

3

$\operatorname{Arg}(\mathrm{R})$

25

Pro (P)

48

Hyp

83

TEAA

101

THAA

125

Imino acids

629

184

Asx $=$ Asp + Asn; Glx = Glu + Gln.

TEAA $=$ total essential amino acids. : $\sum$ Ile+Leu+Lys+Met+Phe+Thr+Val+His. Trp content was not calculated.

THAA $=$ total hydrophobic amino acids: $\sum$ Pro+Ala+Val+Met+Gly+Ile+Leu+Phe. Imino acids $=$ Pro + Hyp . 
Table 2. Viscoelastic parameters $(\mathrm{Mean} \pm \mathrm{SD})$ of BSG.

\begin{tabular}{ll}
\hline $\begin{array}{l}\text { Viscoelastic } \\
\text { parameters }\end{array}$ \\
\hline $\mathrm{G}_{0}{ }^{\circ} 5^{\circ} \mathrm{C}(\mathrm{Pa})$ & $1021 \pm 51.25$ \\
$\mathrm{G}_{0}{ }^{\prime} 5^{\circ} \mathrm{C}(\mathrm{Pa})$ & $15.41 \pm 0.571$ \\
$\mathrm{n}^{\prime} 5^{\circ} \mathrm{C}$ & $0.068 \pm 0.003$ \\
$\mathrm{n}^{\prime} 5^{\circ} \mathrm{C}$ & $0.333 \pm 0.016$ \\
$\delta 5^{\circ} \mathrm{C}$ & $0.851 \pm 0.031$ \\
$\mathrm{Tg}\left({ }^{\circ} \mathrm{C}\right)$ & 10 \\
$\mathrm{Tm}\left({ }^{\circ} \mathrm{C}\right)$ & 22 \\
$\eta^{*} 40^{\circ} \mathrm{C}(\mathrm{Pa} . \mathrm{s})$ & $0.017 \pm 0.000$ \\
$\eta_{\mathrm{m}} * 40^{\circ} \mathrm{C}(\mathrm{Pa} . \mathrm{s})$ & $0.031 \pm 0.002$ \\
$\delta 40^{\circ} \mathrm{C}$ & $89.34 \pm 3.622$ \\
\hline
\end{tabular}




\section{Table 3.}

Emulsifying and foaming properties of barbel skin gelatin (BSG) at different concentrations.

Values are given as mean \pm SD from triplicate determinations.

\begin{tabular}{|c|c|c|c|c|c|c|}
\hline \multicolumn{2}{|c|}{ Concentration } & $0.5 \%$ & $1 \%$ & $2 \%$ & $3 \%$ & $4 \%$ \\
\hline \multicolumn{2}{|c|}{ FE $(\%)$} & $100.5 \pm 0.92$ & $105.0 \pm 2.72$ & $111.5 \pm 2.02$ & $121.13 \pm 1.86$ & $129.0 \pm 2.59$ \\
\hline \multirow[t]{2}{*}{ FS $(\%)$} & $30 \mathrm{~min}$ & $80.0 \pm 0.82$ & $90.0 \pm 0.85$ & $102.6 \pm 0.84$ & $110.5 \pm 0.84$ & $119.0 \pm 2.01$ \\
\hline & $60 \mathrm{~min}$ & $72.51 \pm 1.05$ & $75.0 \pm 1.02$ & $87.5 \pm 0.95$ & $100 \pm 2.60$ & $103.1 \pm 0.92$ \\
\hline \multicolumn{2}{|c|}{ EAI $\left(\mathrm{m}^{2} / \mathrm{g}\right)$} & $16.99 \pm 0.65$ & $22.98 \pm 1.05$ & $26.99 \pm 0.44$ & $31.97 \pm 0.74$ & $37.96 \pm 1.39$ \\
\hline \multicolumn{2}{|c|}{ ESI (min) } & $52.42 \pm 0.65$ & $43.35 \pm 0.98$ & $38.05 \pm 1.49$ & $34.09 \pm 0.95$ & $25.03 \pm 0.12$ \\
\hline
\end{tabular}

EAI $=$ emulsifying activity index

$\mathrm{ESI}=$ emulsion stability index

$\mathrm{FE}=$ Foam expansions

$\mathrm{FS}=$ foam stability

Table 4. 
Dipeptidyl peptidase-IV and prolyl endopeptidase-inhibiting activity of barbel skin gelatine and its hydrolysates. Different letters $(\mathrm{a}, \mathrm{b}, \mathrm{c} \ldots)$ in the same column indicate significant differences among samples.

\begin{tabular}{lccccc}
\hline Enzyme used & $\begin{array}{c}\text { Temperature } \\
\left({ }^{\mathbf{0}} \mathbf{C}\right)\end{array}$ & $\mathbf{p H}$ & $\begin{array}{c}\text { DH } \\
(\mathbf{\%})\end{array}$ & $\begin{array}{c}\mathbf{C I}_{\mathbf{5 0}} \mathbf{D P P}-\mathbf{I V} \\
(\mathbf{m g} / \mathbf{m L})\end{array}$ & $\begin{array}{c}\text { CI } \mathbf{5 0} \text { PEP } \\
(\mathbf{m g} / \mathbf{m L})\end{array}$ \\
\hline $\begin{array}{l}\text { Barbell skin } \\
\text { gelatine }\end{array}$ & - & - & - & no inhibition & $73.97 \pm 27.85$ \\
\hline Esperase 0.8L & 50 & 8 & 9.29 & $2.21 \pm 0.06^{\mathrm{a}}$ & $1.19 \pm 0.23^{\mathrm{ab}}$ \\
\hline Savinase 16L & 55 & 8 & 9.21 & $2.71 \pm 0.19^{\mathrm{a}}$ & $1.95 \pm 0.09^{\mathrm{d}}$ \\
\hline Alcalase 2.4L & 50 & 8 & 14.17 & $2.62 \pm 0.06^{\mathrm{a}}$ & $1.68 \pm 0.09^{\mathrm{cd}}$ \\
\hline Pancreas Trypsin & 50 & 8 & 8.48 & $2.49 \pm 0.03^{\mathrm{a}}$ & $0.91 \pm 0.11^{\mathrm{a}}$ \\
\hline Izyme G & 50 & 8 & 5.74 & $3.71 \pm 0.38^{\mathrm{b}}$ & $1.52 \pm 0.15^{\mathrm{bc}}$ \\
\hline Protamex & 50 & 8 & 10.38 & $2.43 \pm 0.10^{\mathrm{a}}$ & $1.78 \pm 0.01^{\mathrm{cd}}$ \\
\hline Neutrase 0.8L & 50 & 7 & 9.45 & $2.75 \pm 0.33^{\mathrm{a}}$ & $1.79 \pm 0.01^{\mathrm{cd}}$ \\
\hline Peptidase & 50 & 7 & 7.43 & $2.74 \pm 0.06^{\mathrm{a}}$ & $3.79 \pm 0.03^{\mathrm{e}}$ \\
\hline
\end{tabular}


Recovery, visoelastic and functional properties of Barbel skin gelatine: Investigation of anti-DPP-IV and anti-prolyl endopeptidase activities of generated gelatine polypeptides

Assaâd Sila ${ }^{1}$, Oscar Martinez-Alvarez ${ }^{2}$, Anissa Haddar ${ }^{3}$, M. Carmen Gómez-Guillén ${ }^{2}$, Moncef Nasri ${ }^{4}$, M. Pilar Montero ${ }^{2}$ and Ali Bougatef ${ }^{*}$

\section{Research Highlights}

- Gelatin was extracted from freshwater barbel skin.

- Gelatin extraction was improved using a barbel crude acid protease extract.

- The amino acid profile of barbel gelatine showed a high percentage of imino acids.

Barbel gelatine protein hydrolysates (BGPH) were obtained by proteases hydrolysis.

- BGPH are a good source of natural inhibitors of DPP-IV and prolyl endopeptidase. 